\title{
The relationship between neutrophil/lymphocyte ratio and clinical and radiological findings in patients with nonfunctional adrenal incidentaloma
}

\author{
Yilmaz $\mathrm{MO}^{1}$, Keles $\mathrm{FO}^{2}$ \\ Hatay Mustafa Kemal University, Faculty of Medicine, Endocrinology and Metabolism Department, \\ Serinyol, Hatay, Turkey. mugeozsan@gmail.com
}

\begin{abstract}
OBJECTIVES: Although the data in the literature regarding the etiopathogenesis of adrenal adenomas are scarce, the neutrophil/lymphocyte ratio (NLR) is an easy-to-calculate parameter that has gained popularity in recent years as an indicator of subinflammation. In this study, we aimed to show the changes in NLR in patients with adrenal incidentaloma.

METHODS: The anamnesis, laboratory and radiology records of the patients with adrenal incidentaloma in the last 1 year were examined. Functional adrenal incidentalomas were excluded.

RESULTS: The records of clinical, laboratory and radiological findings of 60 patients were examined. The mean neutrophil/lymphocyte ratio was found to be $2.49 \pm 1.29(0.89-6.84)$. There was no relationship between $\mathrm{NLR}$, biochemical parameters and hormone levels. A weakly positive correlation was found between NLR and mass size $(p=0.04 ; r=0.26)$.

CONCLUSION: Adrenal incidentaloma has become one of the clinical problems frequently encountered by endocrinologists in recent years. Even when they are nonfunctional, they are thought to be associated with various metabolic disorders and inflammation. With this study, we have captured a clue to inflammation, and we are sharing the findings described herein (Tab. 1, Ref. 28). Text in PDF www.elis.sk KEY WORDS: adrenal, neutrophil, lymphocyte.
\end{abstract}

\section{Introduction}

Adrenal incidentalomas are adrenal masses that were previously unknown and unsuspected and then incidentally detected during radiological imaging performed for other reasons. The development in abdominal imaging techniques and technology as well as frequent demand of employing these methods for diagnostic purposes have brought about an increase in the cases diagnosed with adrenal incidentaloma (AI). The prevalence of AI has been shown to be $2.3 \%$ on autopsy and $0.5-2 \%$ on computed tomography (CT) scanning (1). The prevalence of adrenal incidentalomas increases with age. Its prevalence is $0.2 \%$ in patients who are in their twenties-thirties, and it increases to $7 \%$ in patients over the age of 70 years (2).

It is an important point in the management of AI cases to determine whether the detected incidentaloma is functional or not. Although most of incidentalomas (more than $80 \%$ ) are benign and

${ }^{1}$ Hatay Mustafa Kemal University, Faculty of Medicine, Endocrinology and Metabolism Department, Hatay, Turkey, and ${ }^{2}$ Hatay Mustafa Kemal University, Faculty of Medicine, Radiology Department, Hatay, Turkey

Address for correspondence: M.O. Yilmaz, Hatay Mustafa Kemal University, Faculty of Medicine, Endocrinology and Metabolism Department, Serinyol, 31006, Hatay, Turkey.

Phone: 05325913735 non-functional, a small portion may secrete excessive hormones (cortisol, aldosterone, catecholamines) or be malignant (primary adrenal tumors, metastasis) (3). The first questions that need to be answered in the approach to adrenal masses detected incidentally are whether the mass has a malignant potential and the second one is whether the mass causes a disease characterized by excessive hormone production (4). While non-functional adenomas that are smaller than $4 \mathrm{~cm}$ can be followed up, the functional adenomas have an absolute surgical indication. Therefore, biochemical and radiological evaluations and multidisciplinary approach are important (5).

The etiopathogenesis of AIs is not fully known. Insulin-like growth factor-1 (IGF-IR) and insulin-related tumorigenesis have been blamed, and there are studies showing that there is a relationship between AI and insulin resistance. It has also been shown that $\mathrm{AI}$ is a component of metabolic syndrome such as obesity, type 2 diabetes, hypertension, hyperlipidemia and fatty liver disease $(6,7)$.

Computed tomography is the most common imaging method of detecting incidentalomas. While the diagnosis of adenoma can be made easily by evaluating the density value by means of unenhanced CT, the differential diagnosis can be made with dynamic CT in cases that are in between. Showing the presence of intracytoplasmic fat on CT is an important criterion in the differential diagnosis of benign/malignant adrenal masses (8). In addition to CT, the in-phase and out-of- phase gradient echo sequence and magnetic resonance imaging (MRI) are also used in adrenal imaging (9). 
493-496

Neutrophil/lymphocyte ratio (NLR) is an increasingly popular indicator which can be calculated using neutrophil and lymphocyte values available as part of whole blood test. NLR is generally accepted as an indicator of subclinical inflammation (10). Significant increase is observed in both CRP and NLR values in metabolic syndrome components (11). In some studies, it has been shown that NLR is an independent prognostic factor in various solid malignancies (12).

In this study, we tried to find out whether there is a relationship between adrenal incidentaloma and neutrophil/lymphocyte ratio.

\section{Materials and methods}

Patients with adrenal incidentaloma treated at the outpatient clinic of Endocrinology and Metabolism Department between August 2018 and August 2019 were included in the study. The approval for the study was obtained from Hatay Mustafa Kemal University Retrospective Studies Ethics Committee (08/08/2019, decision number 15). In this retrospective study, the anamnestic, laboratory and radiology records that had been stored in the hospital registry system were examined. Age, gender, comorbid diseases, and laboratory findings were analyzed.

For the evaluation of hormonal activity, dexamethasone (DST) suppression test (1 $\mathrm{mg}$ dexamethasone given at 23:00 at night and cortisol value checked at 08:00 in the morning) and 24-hour urinary metanephrine and normetanephrine levels were measured. Plasma renin activity (PRA) and aldosterone level were measured to rule out primary hyperaldesteronism in hypertensive patients. Aldosterone/plasma renin activity ratio was calculated. In this way, adrenal incidentaloma was evaluated, and functional adrenal incidentalomas were excluded. Radiological images (CT, MRI) of the patients were reinterpreted by the same radiodiagnostics specialist. Direction, size, image features and radiological diagnoses were recorded.

\section{Statistical Analysis}

IBM SPSS Statistics for Windows (Version 21.0, IBM Corp., Armonk, NY, USA) was used for statistical analyses. Data were presented as mean \pm standard deviation or median and range for continuous variables. Kolmogorov-Smirnov test was used to assess normal distribution of the data. Frequencies were compared using the chi-square test or Fisher's exact test as appropriate. Continuous variables were compared using Student's t-test. Correlation analyses were done with Spearman correlation test. The results were evaluated within a $95 \%$ confidence interval. Statistical significance was set at $\mathrm{p}<0.05$.

\section{Results}

The clinical, laboratory and radiological findings of 60 patients, 37 women (61.7\%) and 23 men (38.3\%), were recorded. The mean age of the patients was $53.73 \pm 11.12$ years. There were three possible patterns of localizations distinguished, namely to the right $(\mathrm{n}=29 ; 48.3 \%)$, to the left $(\mathrm{n}=28 ; 46.7 \%)$, and bilateral $(n=3 ; 5 \%)$ (Tab. 1). According to radiological findings, 51 patients
Tab. 1. Main characteristics of patients with nonfunctional adrenal incidentaloma.

\begin{tabular}{lcc}
\hline Feature & & Number $(\%)$ \\
\hline Age (years) & $<40$ & $8(13.3)$ \\
& $40-49$ & $10(16.6)$ \\
& $50-59$ & $24(40.0)$ \\
& $60-69$ & $13(21.6)$ \\
& $\geq 70$ & $5(8.33)$ \\
\hline Gender & & \\
\hline & Male & $23(38.3)$ \\
& Female & $37(61.7)$ \\
\hline Side & & $29(48.3)$ \\
& Right & $28(46.7)$ \\
& Left & $3(5.0)$ \\
\hline
\end{tabular}

had adenomas, 4 patients had cysts, 3 patients had myelolipomas, 1 patient had a lipid-poor adenoma, and 1 patient had malignant features. Mean longest diameter was $25.01 \pm 14.91$ (6-87) $\mathrm{mm}$. When comorbid diseases were evaluated it was recorded that 10 (16.7\%) patients had hypertension, $8(13.3 \%)$ patients had type 2 diabetes, 20 (33.3\%) patients had multiple diseases while the remaining 22 (36.7\%) patients had no comorbidities.

The mean neutrophil/lymphocyte ratio was found to be 2.49 $\pm 1.29(0.89-6.84)$. This ratio was $2.63 \pm 1.46(0.97-6.84)$ in men and $2.40 \pm 1.19(0.89-6)$ in women. There was no relationship between NLR and biochemical parameters and hormone levels. A weakly positive correlation was found between NLR and mass size $(\mathrm{p}=0.04, \mathrm{r}=0.26)$.

\section{Discussion}

The term adrenal incidentaloma describes a heterogeneous picture of varying pathologies, while adrenocortical adenomas are the most common ones. The frequency of detecting adrenal incidentalomas has also increased alongside technological advances in the field of radiodiagnostics. As a result, there was an increase in the frequency of detecting visible lesions in their early period as well as in cases diagnosed with functional subclinical adrenal diseases. The most important problems in incidentalomas are their malignancy and functional status. Approximately $70-85 \%$ of the masses are benign and do not secrete hormones. The remaining $10-15 \%$ secrete hormones (13). We included nonfunctional adrenal lesions in our study.

The prevalence of adrenal incidentalomas increases with age. It has been shown in various publications that it peaked in the fifth and seventh decades of life. While its prevalence is $0.2 \%$ in the second and third decades, it increases to $7 \%$ in patients above the age of 70 years (2). The mean age in our study was found to be $53.73 \pm 11.12$ years. The female-to-male ratio was $1.2-1.3$ as to adrenal masses (14). In the study conducted by Kutbay et al (15), the female-to-male ratio was 2.2 , whereas in the study conducted by Ekinci et al (16), the female-to-male ratio was as high as 4.8 . In our study the ratio was 1.6. 
In the study of Mantero et al (17), it was shown that in 50-60\% of cases, the adrenal incidentalomas were located on the right side, $30-40 \%$ on the left side, and $10-15 \%$ bilaterally. I Our findings were similar to those of Mantero et al inasmuch as they were seen more frequently on the right side. Nearly $47 \%$ of the adrenal incidentalomas in our study were detected on the left, $48 \%$ on the right, and in $5 \%$ of cases they were found bilaterally.

In other studies, it was reported that DM and HT were seen more frequently than other comorbid diseases in nonfunctional adenomas (18). In a multi-center study conducted in Italy involving 1,004 patients with adrenal incidentaloma, the prevalence of hypertension was $41 \%$ and the prevalence of diabetes was $10 \%$ (19). In the study by Erdem et al (20), 33.1\% of patients with AI had HT and $12.9 \%$ had DM. In our AI patients, the prevalence of HT was $16.7 \%$, and that of DM was $13.3 \%$ while $33.3 \%$ of patients had multiple diseases.

Adenomas are the most common adrenal lesions, and most of them can be diagnosed correctly with non-contrast CT examination. However, the masses with the density value equal to or below 10 Hounsfield units (HU) are considered adenomas. Dynamic CT imaging should be performed to distinguish between lipid-poor adenomas with 10-20 HU and malignant ones. Ninety-eight percent sensitivity and $97 \%$ specificity are achieved with the combined application of late contrast CT and non-contrast CT in cases with density being above $10 \mathrm{HU}$. In magnetic resonance imaging (MRI), the chemical shift feature, in-phase and out-of-phase sequence, and adrenal imaging have an important place. Since adenoma contains intracytoplasmic fat, it can be easily diagnosed by suppressing the chemical shift sequence. Non-adenoma lesions can be differentially diagnosed according to other MRI sequence features and enhancement patterns in dynamic series $(8,9)$.

The size, hormonal activity and radiological imaging features of adrenal adenoma are important in their management. Adrenal adenomas that are smaller than $4 \mathrm{~cm}$ are usually benign and do not require surgery. In the first year, CT follow-up and annual hormone follow-up are required at 3-6-month intervals. Adenomas larger than $4 \mathrm{~cm}$ are usually malignant and require surgery. Surgery should be performed when the masses are found to be hormonally active, regardless of their size $(21,22)$.

There are many studies in the literature investigating the relationship between NLR values and some diseases. There are studies showing that in metabolic syndrome, NLR increases along with the increase in the number of neutrophils and decrease in the number of lymphocytes (23). Recently, NLR has also been shown to be an independent prognostic factor in some solid malignancies. In the study conducted by Mochizuki et al (24), the value of NLR was found to be high in adrenal tumors. In a study conducted on primary liver tumors, it is stated that high NLR values are indicators of poor prognosis and vascular invasion of the tumor (25). It was found that there was a positive correlation with NLR cut-off values determined not only in malignant diseases but also in studies conducted on patients with diabetes and hypertension, and on those with acute appendicitis in childhood $(26,27)$. In our study, mean NLR values are higher in comparison to normal values as given in the literature ( 2.63 vs 2.16 in men and 2.40 vs 1.84 in women) (28). While there was no relationship between NLR and biochemical parameters and hormone levels, there was a weakly positive correlation between NLR and mass size in our study, for which, however, the cut-off value could not be determined.

The facts are that our study was a retrospective one, the patients had no pathological diagnosis, and the number of cases included in the study was relatively low. These are considered as limiting factors of our study. Longer-term and preferably prospective studies on larger case series are of benefit for guidance in this area. As a result, increased frequency of imaging tests and hospital admissions for various reasons have recently increased the incidence of revealing the presence of adrenal incidental masses, but knowledge about their etiology is still limited. Nevertheless, this study will contribute to the literature on this subject from different viewpoints.

\section{References}

1. Barzon L, Sonino N, Fallo F, Palu G, Boscaro M. Prevalence and natural history of adrenal incidentalomas. Eur J Endocrinol 2003; 149 (4): 273-285.

2. Kim J, Bae KH, Choi YK, Jeong JY, Park KG, Kim JG, Lee IK. Clinical characteristics for 348 patients with adrenal incidentaloma. Endocrinol Metab 2013; 28 (1): 20-25.

3. Jason DS, Oltmann SC. Evaluation of an Adrenal Incidentaloma. Surg Clin North Am 2019; 99 (4): 721-729.

4. Adrenal Incidentalomas in the Society of Endocrinology and Metabolism of Turkey Adrenal and Gonadal Diseases Guidelines 2019; 77-87.

5. Anagnostis P, Karagiannis A, Tziomalos K, Kakafika AI, Athyros VG, Mikhailidis DP. Adrenal incidentaloma: a diagnostic challenge. Hormones (Athens) 2009; 8: 163-184.

6. Peppa M, Boutati E, Koliaki C, Papaefstathiou N, Garoflos E, Economopoulos T, Hadjidakis D, Raptis SA. Insulin resistance and metabolic syndrome in patients with non-functioning adrenal incidentalomas: a causeeffect relationship? Metabolism 2010; 59: 1435-1444.

7. Midorikawa S, Sanada H, Hashimoto S, Suzuki T, Watanabe T. The improvement of insulin resistance in patients with adrenal incidentaloma by surgical resection. Clin Endocrinol (Oxf) 2001; 54: 797-804.

8. Korobkin M, Brodeur FJ, Francis IR, Quint LE, Dunnick NR, Londy F. CT time-attenuation washout curves of adrenal adenomas and nonadenomas. AJR Am J Roentgenol 1998; 170: 747-752.

9. Mansmann G, Lau J, Balk E, Rothberg M, Miyachi Y, Bornstein SR. The clinically inapparent adrenal mass: update in diagnosis and management. Endocr Rev 2004; 25: 309-340.

10. Zahorec R. Ratio of neutrophil to lymphocyte counts-rapid and simple parameter of systemic inflammation and stress in critically ill. Bratisl Med J 2001; 102: 5-14.

11. Yasar Z, Buyuksirin M, Ucsular FD, Kargi A, Erdem F, Talay F, Kurt OK. Is an elevated neutrophil-to-lymphocyte ratio a predictor of metabolic syndrome in patients with chronic obstructive pulmonary disease? Eur Rev Med Pharmacol Sci 2015; 19 (6): 956-962.

12. Ohno Y, Nakashima J, Ohori M, Hatano T, Tachibana M. Pretreatment neutrophil-to-lymphocyte ratio as an independent predictor of recurrence in patients with nonmetastatic renal cell carcinoma. J Urol 2010; 184 (3): 873-878. 
493-496

13. Grumbach MM, Biller BM, Braunstein GD, Campbell KK, Carney JA et al. Management of the clinically inapparent adrenal mass ("incidentaloma"). Ann Intern Med 2003; 138 (5): 424-429.

14. Tutuncu NB, Gedik O. Adrenal incidentaloma: Report of 33 cases. J Surg Oncol 1999; 70 (4): 247-250.

15. Kutbay NÖ, Yürekli BŞ, Pehlivan E, Makay Ö, Erdoğan M, Çetinkalp Ş, Özgen G, Saygili F. Adrenal insidentalomasi olan 80 hastamizin klinik özellikleri Clinical features of 80 cases with adrenal incidentaloma. Ege Journal of Medicine 2015; 54 (3): 120-123.

16. Ekinci F, Soyaltin UE, Yaşar HY, Akar H, Yildirim TD, Uğur MC, Ersoy E. Sürrenal insidentalomali hastalarin değerlendirilmesi Assessment of adrenal incidentaloma patients. Araştirma Tepecik Eğit. ve Araşt. Hast. Dergisi 2016; 26 (1): 10-14.

17. Mantero F, Terzolo M, Arnaldi G, Osella G, Masini AM, Alì A, Giovagnetti M, Opocher G, Angeli A. A survey on adrenal incidentaloma in Italy. Study Group on Adrenal Tumors of the Italian Society of Endocrinology. J Clin Endocrinol Metab 2000; 85 (2): 637-644.

18. Kloos RT, Gross MD, Francis IR, Francis IR, Korobkin M, Shapiro B. Incidentally discovered adrenal masses. Endocr Rev 1995; 16: 460-484.

19. Angeli A, Osella G, Ali A, Terzolo M. Adrenal insidentaloma: an overview of clinical and epidemiological data from the National Italian Study Group. Horm Res 1997; 47 (4-6): 279-283.

20. Erdem M, Yildiz S. Clinical Radiological Assessment in Patients with Adrenal Incidentaloma. Van Tip Derg 2019; 26 (1): 67-72.

21. Ridho FE, Adam FM, Adam JM. Adrenal incidentaloma. Acta Med Indones 2009; 41 (2): 87-93.
22. Thompson GB, Grant CS, van Heerden JA, Schlinkert RT, Young WF Jr Farley DR, IIstrup DM. Laparoscopic versus open posterior adrenalectomy: a case-control study of 100 patients. Surgery 1997; 122: $1132-1136$.

23. Buyukkaya E, Karakas MF, Karakas E, Akçay AB, Tanboga IH, Kurt M, Sen N. Correlation of neutrophil to lymphocyte ratio with the presence and severity of metabolic syndrome. Clin Appl Thromb Hemost 2014; 20 (2): 159-163.

24. Mochizuki T, Kawahara T, Takamoto D, Makiyama K, Hattori Y, Teranishi JI, Miyoshi Y, Yumura Y, Yao M, Uemura H. The neutrophilto-lymphocyte ratio (NLR) predicts adrenocortical carcinoma and is correlated with the prognosis. BMC Urol 2017; 17 (1): 49.

25. Xue TC, Zhang L, Xie XY, Ge NL, Li LX, Zhang BH, Ye SL, Ren ZG. Prognostic significance of the neutrophil to lymphocyte ratio in primary liver cancer: A meta-analysis. PLoS One 2014; 9 (5): e9 6072.

26. Imtiaz F, Shafique K, Mirza SS, Ayoob Z, Vart P, Rao S. Neutrophil lymphocyte ratio as a measure of systemic inflammation in prevalent chronic diseases in Asian population. Int Arch Med 2012; 5: 2.

27. Narci A, Tuncer AA, Çetinkurşun S. Diagnostic importance of neutrophil/lymphocyte ratio in childhood appendicitis. Med J Kocatepe 2009; 10: $5-7$.

28. Taş A, Honca T, Özgürtaş T, Türker T, Koçak N. Farkli yaş gruplarinda nötrofil/lenfosit orani referans araliklari. Gülhane Tip Derg 2015; 57: 414-418.

Received December 18, 2020. Accepted February 13, 2021. 